\title{
ASPECTOS CRISTOLÓGICOS NA ORAÇÃO "LOUVORES A DEUS ALTÍSSIMO”, DE SÃO FRANCISCO DE ASSIS
}

\author{
Christological Aspects in the Prayer "Praise to the Highest God" of Saint Francis of \\ Assisi
}

\author{
Sidney Damasio Machado ${ }^{1}$ \\ Kleber Moresco ${ }^{2}$
}

\begin{abstract}
RESUMO: Alguns autores medievais intuíram com muita sabedoria o princípio de que o modelo perfeito de ser humano encontra-se em Jesus Cristo; esse princípio hermenêutico vincula o estudo da antropologia com a compreensão cristológica. A experiência pessoal e/ou coletiva interfere diretamente no modo de imaginar Cristo, pois o imaginário é formado com elementos culturais. Sendo assim, as representações de Cristo são herdeiras de uma experiência, essa experiência além de buscar descrever a Cristo, também revela o ideal antropológico, pois Cristo é o ser humano por excelência. Orações, pinturas e escritos são algumas das formas de manifestar de modo metafórico a relação entre o ser humano e o transcendente. Na oração Louvores a Deus Altíssimo São Francisco atribui diversos adjetivos a Deus. O objetivo desse artigo é apresentar alguns elementos cristológicos presentes nessa oração, e a partir desses elementos, perceber os ideais antropológicos presentes na compreensão de São Francisco de Assis.
\end{abstract}

PALAVRAS-CHAVE: Antropologia; Cristologia; Experiência; Representação; Imaginário.

ABSTRACT: Some medieval authors very wisely intuited the principle that the perfect model of human being is found in Jesus Christ; this hermeneutical principle links the study of anthropology with a Christological understanding. Personal and/or collective experience directly interferes in the way of imagining Christ, and imaginary is formed with cultural elements. Thus, the representations of Christ are heirs of an experience, this experience, besides to seeking to describe Christ, also reveals the anthropological ideal, because Christ is the human being par excellence. Prayers, paintings and writings are some of the ways to metaphorically manifest the relationship between the human being and the transcendent. At the Praises to God Highest Saint Francis attributes several adjectives to God. The purpose of this article is to underline some Christological elements present in this prayer, so that we can knowledge some Saint Francis' anthropological ideals.

KEYWORDS: Anthropology; Christology; Experience; Representation; Imaginary.

\footnotetext{
${ }^{1}$ Doutor em teologia pela Pontificia Università Gregoriana (PUG) e é professor de teologia no Claretiano

- Centro Universitário. E-mail: sidneymachado@claretiano.edu.br

${ }^{2}$ Licenciado em Filosofia pela Faculdade Entre Rios do Piauí (FAERPI) e bacharel em teologia pelo

Claretiano - Centro Universitário. E-mail: klebmoresco@ hotmail.com
} 
A oração Louvores a Deus Altíssimo apresenta muitos elementos cristológicos sintetizados a partir da experiência mística e da vida de São Francisco de Assis na forma de um escrito. Esses diversos elementos unem-se formando uma complementariedade, gerando um ponto de vista profundamente pessoal e também inovador. O escrito de Francisco é uma oração que visa louvar a Deus; mesmo sem ter a pretensão de fazer uma sistematização teológica sobre Deus, a experiência de São Francisco é profundamente teológica e portadora de uma leitura muito encarnada da Sagrada Escritura.

A autenticidade desta oração não é colocada em dúvida, pois ela está contida em um dos raros autógrafos do santo que chegaram até os nossos dias, a famosa Chartula fratri Leoni data. ${ }^{3}$ Indícios apontam que a oração tenha sido escrita entre agosto e dezembro de 1224, no período em que o santo estava no Monte Alverne, logo após ter recebido os estigmas de Cristo. É um dos últimos escritos de São Francisco, ${ }^{4}$ que conforme o relato de Celano, "escreveu de próprio punho os louvores de Deus, e as palavras que quis e, por fim, a bênção". ${ }^{5} \mathrm{O}$ próprio frei Leão, que conservou o manuscrito e levou consigo durante toda a vida, fez sobre ele anotações importantes a respeito de sua origem e data. ${ }^{6}$ Portanto, o citado pergaminho contém tanto a benção a Frei Leão, quanto os Louvores ao Deus Altíssimo, aqui transcrita:

\author{
Laudes Dei Altissimi [LaudDei] \\ ${ }^{[1]}$ Tu es sanctus Dominus Deus solus, qui facis mirabilia $(\mathrm{Sl} \mathrm{76,15)})^{7}$. \\ ${ }^{[2]} \mathrm{Tu}$ es fortis, Tu es magnus, Tu es altissimus (cf. Sl 85,10), \\ ${ }^{[3]} \mathrm{Tu}$ es omnipotens, Tu Pater sancte (Jo 17,11), rex caeli et \\ ${ }^{[4]}$ terre (cf. Mt 11,25). Tu es trinus et unus, Dominus Deus \\ ${ }^{[5]}$ deorum (cfr. Sl 135,2), tu es bonum, omne bonum, \\ summum bonum, \\ ${ }^{[6]}$ Dominus Deus vivus et verus.
}

Tu es amor, caritas,

${ }^{[7]} \mathrm{Tu}$ es sapientia, Tu es humilitas, Tu es pacientia (cf. S1 70,5),

${ }^{[8]} \mathrm{Tu}$ es pulchritudo, Tu es securitas; Tu es quie-

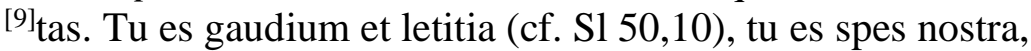

Tu es iustitia

${ }^{[10]}$ et temperantia, Tu es omnia divitia nostra a(d) sufficientiam.

\footnotetext{
${ }^{3}$ O pergaminho está preservado na Basílica de São Francisco, em Assis e mede 10 x 13,5 cm. LANGELI, Attilio Bartoli. Gli autofrafi di frate Francesco e di frate Leone. Turnhout: Brepols, 2000, p. 13.

${ }^{4}$ Fontes Franciscanas e Clarianas. [trad.: Celso Márcio Teixeira, et. al]. Petrópolis: Vozes, 2004, p. 87.

52 Cel 49.

${ }^{6}$ As fontes atestam que frei Leão, já perto de sua morte, doou o manuscrito às Damas pobres de São Damião, contudo, desde 1338 o documento constava no inventário da sacristia do Sacro Convento de Assis. LANGELI, Attilio Bartoli. Gli autofrafi di frate Francesco e di frate Leone. Turnhout: Brepols, 2000, p. $31 \mathrm{~s}$.

${ }^{7}$ Por questão metodológica, as abreviaturas bíblicas são apresentadas conforme abreviaturas em português.
} 
${ }^{[11]} \mathrm{Tu}$ es pulchritudo, Tu es mansuetudo,

${ }^{[12]} \mathrm{Tu}$ es protector $(\mathrm{Sl} 30,5), \mathrm{Tu}$ es custos et defensor,

${ }^{[13]} \mathrm{Tu}$ es fortitudo (cf. S1 42,2), tu es refugium.

Tu es spes

${ }^{[14]}$ nostra, Tu es fides nostra, Tu es caritas

${ }^{[15]}$ nostra, Tu es tota dulcedo nostra, Tu es

${ }^{[16]}$ vita aeterna mostra, magnus et admirabilis

${ }^{[17]}$ Dominus, Deus omnipotens, misericors Salvator. ${ }^{8}$

A proposta de tradução e estrutura dos Louvores ao Deus Altíssimo apresentada por Lehmann é a seguinte9.

\section{[Parte I]}

Vós sois santo, Senhor Deus único, que fazeis maravilhas (S1 74,15).

Vós sois forte, vós sois grande (cf. Sl 85, 10), vós sois Altíssimo, vós sois rei onipotente, vós Pai Santo (Jo 17, 11), rei do céu e da terra (cf. Mt 11, 25).

Vós sois trino e uno, Senhor Deus dos deuses (cf. Sl 135, 2), vós sois o bem, todo bem, o sumo bem, Senhor Deus vivo e verdadeiro (cf. 1Ts 1,9).

\section{[Parte II]}

Vós sois amor, caridade; vós sois sabedoria, vós sois humildade, vós sois paciência ( $\mathrm{Sl}$ $70,5)$, vós sois beleza, vós sois mansidão, vós sois segurança, vós sois descanso, vós sois gozo, vós sois nossa esperança e alegria, vós sois justiça, vós sois temperança, vós sois a plenitude da riqueza.

[Parte III]

Vós sois beleza, vós sois mansidão, vós sois protetor (S1 30, 5), vós sois guarda e defensor nosso; vós sois fortaleza (cfr. S1 42, 2), vós sois refrigério.

Vós sois nossa esperança, vós sois nossa fé, vós sois nossa caridade, vós sois toda doçura nossa, vós sois nossa vida eterna, Grande e admirável Senhor, Deus onipotente, misericordioso Salvador.

Francisco compõe esse louvor estando quase cego, com algumas doenças e sentindo muitas dores provocadas pelos estigmas. Diante da experiência de sofrimento, transborda de amor e com ternura consegue consolar Leão, mesmo tendo consciência de que o momento da sua morte se aproxima. Por este motivo ele deixa uma preciosa herança para o seu companheiro. Enquanto Leão fixa seu olhar no sofrimento e na iminência da morte; Francisco contempla a beleza e a bondade de Deus Altíssimo. Com essa oração ele quer arrastar Leão para a imensidão do amor que lhe conduz a Deus. ${ }^{10} \mathrm{O}$ foco não é o momento da morte e o sofrimento, mas a confiança em Deus.

\footnotetext{
${ }^{8}$ Francesco d'Assisi. Scritti. Grottaferrata: Ad Claras Aquas, 2009, p. 112-114.

${ }^{9}$ LEHMANN, Leonard. Francisco Mestre de Oração. Trad.: José Carlos Correia Pedroso. Piracicaba: CEFEPAL, 1997, p. 163-174.

${ }^{10}$ BARSOTTI, Divo. Una teologia dell'esperienza di Dio: Le laudes Dei di S. Francesco d'Assisi. In: Contratto, 4 (1995), p. 76.
} 
A experiência no Monte Alverne foi a marca sensível de um processo de configuração com Cristo que envolveu a totalidade da vida de Francisco. Seu testemunho de vida manifesta que a experiência de encontro com o Crucificado no Alverne e a impressão das chagas se concretizam como uma explosão de amor, compaixão e misericórdia, mas terminam por transformar qualitativamente o modo como encarava a vida. ${ }^{11}$

Francisco nos seus escritos não descreve a sua experiência com o Senhor no alto do Alverne, todavia, manifesta espontaneamente esse encontro por meio de alguns recursos linguísticos, ${ }^{12}$ como: a justaposição de frases afirmativas, o uso reiterado de alguns termos, a utilização do superlativo e de expressões que indicam exclusividade e totalidade. Deste modo, ele manifesta naturalmente a potente ressonância afetiva da experiência mística que lhe foi descortinada; ${ }^{13}$ os escritos, a vida, o relacionamento com as pessoas e com toda a criação são testemunhas desta experiência. A inspiração dos Louvores ao Deus Altíssimo possui raízes tanto litúrgicas quanto místicas, ${ }^{14}$ portanto, Francisco torna de sua vida um lugar teológico de encontro e atualização da Palavra de Deus, a manifestação desse processo se dá em forma de oração de louvor.

\section{Vós sois santo - considerações sobre a primeira parte da oração}

Os louvores apresentam um tom de oração litânica, onde o uso do pronome "Tu" (traduzido livremente por "Vós" em português) indica a proximidade entre as partes envolvidas no diálogo. Essa primeira parte da oração apresenta o aspecto transcendente de Deus. Há uma demonstração da grandeza, do poder e da bondade de Deus como manifestação de sua transcendência, onde o emprego do superlativo "Altíssimo" revela a paradoxal necessidade e incapacidade de falar sobre Deus e suas qualidades.

Há um único momento da oração em que se nomeia o agir de Deus, "Senhor Deus único, que fazeis maravilhas", nas demais estrofes existe uma contínua atribuição de adjetivos a Deus. "Aprouve a Deus, na sua bondade e sabedoria, revelar-se a Si mesmo", ${ }^{15}$

\footnotetext{
11 Escritos de São Francisco de Assis. 2. ed. Santo André: Mensageiro de Santo Antônio, 1999, p. 235238.

12 As palavras "descrever" e "manifestar" são empregadas conforme a diferenciação que Wittgenstein faz delas na obra Tractatus Logico-Philosophucus. PESSI, Donizeti; MORESCO, Kleber. A estrutura lógica e os limites da descrição do mundo. In: Controvérsia 15, (2019), p. 107-116.

${ }^{13}$ MACHADO, Sidney Damasio. L' “Altissimo" e il "Santissimo”. Studio semantico e simbolico di due termini chiave degli "Scritti” di san Francesco d'Assisi. Roma: Istituto Storico de Cappuccini, 2019, p. 209s.

${ }^{14}$ PAOLAZZI, Carlo. Lettura degli Scritti di Francesco d'Assisi. Milano: Francescana, 2015, p. 115.

${ }^{15}$ CONCÍLIO ECUMÊNICO VATICANO II. Constituição dogmática “Dei Verbum”. São Paulo: Paulinas, 1966, p. 4.
} 
Deus revela-se no mundo por meio do seu agir. Toda manifestação de Deus é um sinal do seu desejo amoroso de revelar-se ao ser humano, sendo que, a maior revelação divina está na encarnação, vida e paixão de Jesus Cristo. Jesus Cristo é a plenitude da revelação e do agir de Deus na história.

Francisco participa da compreensão de que o ápice da revelação acontece por meio de Cristo. Na oração Louvores a Deus Altíssimo são reconhecidos em Deus os atributos, Santo, Grande, Altíssimo, Onipotente, Rei do céu e da terra, Deus dos deuses, Sumo bem. Esses elementos manifestam a síntese perfeita e paradoxal de Cristo, que integra em si a humanidade e divindade; a fragilidade e o poder; a pobreza e a realeza. Francisco apresenta na oração elementos de uma cristologia do alto, mas na sua vida, vive de acordo com a pobreza de Jesus Cristo.

O emprego da palavra "Santo" possui como referência direta ou indireta a divindade. A análise da forma como Francisco emprega essa palavra nos demais escritos, revela a íntima relação entre esse adjetivo e a pessoa de Cristo. ${ }^{16}$ A palavra "Santo" é utilizada para descrever:

- 21 vezes o Espírito Santo. ${ }^{17}$

- 2 vezes os Santos Sacerdotes. ${ }^{23}$

- 9 vezes o Santo Evangelho. ${ }^{18}$

- 2 vezes o Santo Filho. ${ }^{24}$

- 6 vezes os Santos de Deus. ${ }^{19}$

- 1 vez o santo amor ${ }^{25}$,

- 4 vezes o Pai Santo. ${ }^{20}$

- 3 vezes o Deus Santo. ${ }^{21}$

- 2 vezes a Festa dos Santos. ${ }^{22}$

- 1 vez o santo jejum ${ }^{26}$,

- 1 vez a santa eucaristia ${ }^{27}$

- 1 vez os santos apóstolos. ${ }^{28}$

Essa constante referência à santidade nos escritos de Francisco é uma marca da modalidade mística da sua experiência religiosa. O termo "Santo" não serve apenas para indicar a sensibilidade de Francisco para com a transcendência divina, mas demonstra a

\footnotetext{
16 A mesma dinâmica se verifica nos Escritos de Francisco quanto ao superlativo "santíssimo" que é maiormente aplicado ao Filho, ou às formas de sua presença sobre a terra (a Palavra, a Eucaristia). MACHADO, Sidney. Ver para crer: um percurso espiritual artístico e simbólico. São Paulo: Angelus, 2021, p. 99-103.

${ }^{17}$ Adm 1,7; Adm 8,1; RnB 16,7 (2X); RnB 17,16; RnB 21,2; RnB 22,27; RnB 23,5; RnB 23,6; RnB 23,11;

FV 1; 1 Fi 8; 1 Fi 12; Ord 1; Ord 33; Ord 38; Ord 51; LH 4; LH 9; SM 2; SM 6.

${ }^{18}$ Test 14; RnB 5,17; RnB 22,41; RB 1,1;RB 2,5; RB 2,13; RB 3,14; RB 12,4; FV 1 .

${ }^{19}$ Adm 6,3; Test 40; Rnb 23,6; 1 Ct 2; Ord 38; PN 2.

${ }^{20} \mathrm{RnB} 22,45 ; \mathrm{RnB} 23,1 ; 1 \mathrm{Fi} 11 ; 1 \mathrm{Fi} 14$.

${ }^{21} \mathrm{RnB}$ 23,9; OC 5; LH 1 .

${ }^{22} \operatorname{RnB} 3,11 ; \operatorname{RB} 3,5$.

${ }^{23}$ Ord 22; Ord 23.

${ }^{24} 1 \mathrm{Fi} 13$; Ord 23.

${ }^{25} \operatorname{RnB} 23,3$.

${ }^{26} R B 3,6$.

${ }^{27}$ Ord 19.

${ }^{28} \mathrm{Adm} 1,19$.
} 
percepção que ele possuía quanto a peculiaridade do agir de cada uma das pessoas da Trindade. ${ }^{29}$ Não é por acaso que Francisco parte da Trindade, modelo de igualdade entre as pessoas, quando fala da fraternidade. A Trindade não é um Deus que se desdobra em três; são três pessoas, que formam uma fraternidade perfeita. ${ }^{30}$ Qualquer traço de arianismo ou subordinacionismo estaria em dissonância com daquilo que é proposto como ideal de fraternidade.

A partir da igualdade existente entre as pessoas da Trindade podemos afirmar categoricamente que existe sim uma teologia da pré-existência do Verbo nas orações de Francisco de Assis. Ao mesmo tempo em que existe um longo discurso evocando características de Cristo como "Rei Onipotente", existe também o emprego de diversas características muito concretas e muito humanas. Desse modo, Francisco compreende a união profunda existente entre as pessoas da Trindade. Duas expressões bíblicas empregadas dentro dessa primeira parte são "Pai Santo" (Jo 17,11) e "Rei do céu e da terra" (Mt 11,25). Esses dois textos estão situados dentro das orações que Jesus dirige ao Pai, afirmando a proximidade e igualdade entre ambos.

A linguagem de Francisco está permeada de algumas expressões, como por exemplo: "Vós sois rei onipotente, vós, ó Pai santo, [sois] o rei do céu e da terra". Por muito tempo, o Poverello identificou a si e seus companheiros como cavaleiros a serviço de Deus. A cavalaria cultivava virtudes como a fidelidade, o respeito e a bravura. O cavaleiro possuía o encargo de cumprir sua tarefa, ainda que para isso fosse necessário entregar sua vida. Francisco parte de uma experiência cavalheiresca, mas aprofunda seu sentido ao afirmar "Vós sois nossa vida eterna: grande e admirável Senhor, Deus onipotente, misericordioso Salvador"; o que está em jogo não é o cumprimento da missão, mas o conhecimento do Senhor por meio da Criação e de suas ações.

No serviço de evangelização, o envio, a missão e o resultado pertencem a Deus. Esse conhecimento permite a confiança de afirmar "Vós sois justiça, vós sois temperança"; ao mesmo tempo em que reafirma a onipotência de Deus como "rei onipotente" e "altíssimo". O supremo poder de Deus encontra-se em relação com a justiça e a temperança em todos os seus atos, afastando o medo do julgamento e do fracasso. Deus

\footnotetext{
29 BERNARD, Charles Andrè. L'esperienza spirituale della Trinità. In: La mistica. Fenomenologia e riflessione teologica. [II]. Roma: Città Nuova, 1984, p. 296.

${ }^{30}$ LEHMANN, Leonard. Francisco Mestre de Oração. Piracicaba: CEFEPAL, 1997, p. 166.
} 
é representado como Rei e Juiz, que vem para julgar, mas com mansidão e clemencia. ${ }^{31}$ Francisco não costuma usar frequentemente a palavra Rei, contudo, dentro dos seus escritos ele cita:

- 2 vezes os reis e príncipes. ${ }^{32}$

- 1 vez o Rei de Israel..$^{35}$

- 1 vez o Sumo Rei. ${ }^{33}$

- 1 vez os Reis do Reino dos Céus. ${ }^{36}$

- 1 vez o Rei do céu. ${ }^{34}$

A palavra "rei" designa um homem que possui funções administrativas em um determinado local. No entanto, Francisco inverte essa referência ao aplicar esse título a Deus: não é o Altíssimo que se assemelha aos reis terrenos. Essa oração de Francisco convoca os reis a buscarem a configuração com Deus, pois Ele é o rei por excelência. $\mathrm{Na}$ carta aos governantes, Francisco recorda que "o dia da morte se aproxima", ${ }^{37}$ exortando todos à prática das boas obras, pois a dimensão messiânica de salvação acontece em dois momentos: 1 - No julgamento de Deus. 2 - Na conquista ou perca do "Reino de Deus". O termo "Reino de Deus" é usado dentro de contextos diferentes, sendo:

- 5 vezes entrar no Reino de Deus.38

- 4 vezes perder o Reino de Deus.39
- 3 vezes o Reino é o lugar de Deus.40

- 3 vezes relacionando os pobres com o Reino de Deus.41

A experiência de Francisco integra elementos culturais, com uma dimensão apocalíptica escatológica, ${ }^{42}$ propondo a inversão da ordem vigente, uma vez que os pobres são possuidores do Reino e aqueles que são sábios conforme o mundo, perderão o Reino

\footnotetext{
${ }^{31}$ MOLINA PARRA, Néstor Bernardo. El Reino de Dios en el pensamiento eclesiológico y escatológico de san Francisco de Asís, según sus escritos y las fuentes hagiográficas del siglo XIII-XIV. Murcia: Espigas, 2015, p. 138.

${ }^{32} \operatorname{RnB} 2,14 ; \operatorname{RnB} 23,7$.

${ }^{33} \mathrm{FV} 1$.

${ }^{34} \mathrm{RnB} 23,1$.

${ }^{35}$ ExL 8.

${ }^{36} R B$ 6,4.

${ }^{37} G v 2$.

${ }^{38} R n B$ 16,7; RnB 16,12; RnB 21,7; RnB 23,4; RB 10,11.

${ }^{39} R n B$ 2,10; RnB 8,5; RB 2,13; $2 F i 23$.

${ }^{40} \mathrm{RnB} 22,55 ; 2 \mathrm{Fi} 60 ; \mathrm{PN} 4$.

${ }^{41} A d m$ 14,1; RnB 2,15; RB 6,4.

${ }^{42}$ MOLINA PARRA, Néstor Bernardo. El Reino de Dios en el pensamiento eclesiológico y escatológico de san Francisco de Asís, según sus escritos y las fuentes hagiográficas del siglo XIII-XIV. Murcia: Espigas, 2015, p. 140.
} 
dos céus. Existe um alerta implícito especialmente aos reis, se eles não buscarem a sabedoria divina, poderão perder o Reino dos céus.

Francisco manifesta clareza quanto ao fato de que o Reino pertence a Deus, e de que não são os méritos humanos que conquistam esse Reino. Somente mediante a misericórdia de Deus, o esforço pessoal pode abrir as portas desse Reino. A imagem do Rei e juiz, que é misericordioso e bondoso serve de modelo para os governantes. Essa imagem emerge da vida e do imaginário de Francisco, o cavaleiro do mais nobre entre os Senhores.

\section{Vós sois amor, caridade - considerações sobre a segunda parte da oração}

A segunda parte apresenta 13 [ou 14, conforme a contagem] invocações sobre Deus. O Amor aparece como primeiro elemento e reaparece dentro dessa mesma estrofe. As características atribuídas a Deus são muito humanas, e também muito relacionadas com a encarnação.

A vida de Jesus na terra torna presente, de maneira definitiva, a ação de Deus em nossa história, abre os olhos de nossa fé, revela ao que crê todo o agir divino, desde a criação até a consumação total, como única e completa obra salvífica de Deus. ${ }^{43}$

A afirmação "Vós sois sabedoria" retoma diversas heranças veterotestamentárias, contudo, a afirmação "Vós sois humildade" só pode ser concebida a partir do Novo Testamento. Toda a vida de Jesus é uma prova de humildade, mas Francisco identifica três momentos particularmente especiais: a encarnação, o processo de crucificação/morte e a eucaristia. ${ }^{44}$ Esse paradoxo da grandeza que se humilha é fundamental dentro da espiritualidade de Francisco e do movimento Franciscano. ${ }^{45}$ A forma como o Santo utiliza a palavra "sabedoria" revela uma dimensão cristológica ao afirmar: "Não têm a sabedoria espiritual, porque não têm o Filho de Deus, que é a verdadeira sabedoria do Pai”. ${ }^{46}$ Seguindo quanto oferecido pela tradição patrística, a Sabedoria é identificada com a pessoa de Jesus Cristo e com suas atitudes.

\footnotetext{
${ }^{43}$ Dicionário Franciscano. Petrópolis, RJ: CEFEPAL/Vozes, 1993, p. 360

${ }^{44}$ NGUYÊN-VAN-KHANH, Norbert. Gesù Cristo nel pensiero di San Francesco. Milano: Francescana, 1984. p. 143-154.

45 MACHADO, Sidney Damasio. L' “Altissimo" e il "Santissimo”. Studio semantico e simbolico di due termini chiave degli "Scritti” di san Francesco d'Assisi. Roma: Istituto Storico de Cappuccini, 2019, p. 248. ${ }^{46} 2 \mathrm{Fi} 2,8$.
} 
Existe uma tensão entre alcançar ou não o Reino dos Céus, e os elementos que geram essa tensão estão na disparidade entre a sabedoria do mundo e a sabedoria de Deus. A sabedoria é uma virtude muito estimada e usada com cuidado por Francisco. Em seus escritos ele a utiliza:

- 4 vezes para falar da sabedoria do mundo. ${ }^{47}$

- 3 vezes para identificar Cristo como sendo a sabedoria do Pai. ${ }^{48}$
- 3 vezes fala da sabedoria como divina. ${ }^{49}$

- 2 vezes apresenta-a na dimensão de dom. ${ }^{50}$

- 2 vezes apresenta-a como Rainha. ${ }^{51}$

Esse olhar mais amplo ajuda a mostrar como a espiritualidade de Francisco é herdeira de uma cristologia da Sabedoria. A Sabedoria é personificada ${ }^{52}$ e identificada com Cristo. ${ }^{53} \mathrm{O}$ modo de proceder de Cristo afugenta a ilusória sabedoria do mundo, aproximando as pessoas do Reino de Deus. Como afirma Pompei: "Em Francisco, Cristo foi a origem e a raiz de tudo, Cristo é seu Conselheiro, único Mestre, protótipo exemplar, guia e caminho". ${ }^{54}$ Entretanto, o modo de proceder de Cristo é humilde e se manifesta através de várias atitudes.

A paciência citada nos Louvores, é uma forma de humildade, assim como está afirmado nas admoestações: "O servo não pode saber quanta paciência e humildade tem em si, enquanto está satisfeito consigo [mesmo]"55; é também uma forma de seguimento de Cristo "pois em vossa paciência possuireis vossas almas (Lc 21,19)". ${ }^{56}$ A expressão "humildade" possui uma dimensão de configuração muito grande, esse termo está diretamente relacionado com a pobreza e com o seguimento de Cristo. Cabe ressaltar que Francisco viveu por um tempo em um mosteiro beneditino, e dentro da Regra beneditina a humildade é uma das virtudes mais destacadas. ${ }^{57}$

\footnotetext{
${ }^{47}$ RnB 17,10; 1 Fi 2, 9; 2 Fi 67; SV 9.

48 1 Fi 2, 8; 2 Fi 67; LH 3.

${ }^{49} \mathrm{RnB}$ 17,16; 1 Fi 8; 2 Fi 67.

${ }^{50} \mathrm{Adm}$ 5,6; $\operatorname{Adm} 27,1$.

${ }^{51} S V 1 ; S V 9$.

${ }^{52} \mathrm{SV}$.

${ }^{53}$ NGUYÊN-VAN-KHANH, Norbert. Gesù Cristo nel pensiero di San Francesco. Milano: Francescana, 1984, p. 168-171.

${ }^{54}$ Dicionário Franciscano. Petrópolis, RJ: CEFEPAL/Vozes, 1993, p. 355.

${ }^{55}$ Adm XII, 2.

${ }^{56} \mathrm{RnB} 16,20$.

${ }^{57}$ Regra de São Bento. 3. ed. Juiz de Fora: Edições Subiaco, 2016, p. 38-47/Capítulo VII.
} 
Francisco cita 23 vezes as atitudes humildes, ${ }^{58} 6$ vezes trata sobre a humildade específica de Jesus, ${ }^{59} 5$ vezes trata de características pessoais, ${ }^{60} 3$ vezes apresenta a humildade como um dom ${ }^{61}$ e 2 vezes relaciona a humildade com a Eucaristia. ${ }^{62}$ Das 16 vezes em que Francisco falou de humildade como seguimento, encontramos essas referências principalmente nas formas de vida e admoestações. A preocupação com o exercício da virtude é fundamental, pois a dimensão prática, ou de seguimento, é uma parte integrante da cristologia franciscana. "A cristologia não é apenas ensinamento teórico a respeito da imitação de Cristo, mas se nutre da imitação prática para ser verdadeira". ${ }^{63}$ Todavia, o sentido da prática dessa virtude está no mistério da manifestação do Verbo feito carne, onde a humildade da kenosis fundamenta também a vida de pobreza.

Em seu nexo com a pobreza, a humildade também está associada à alegria, elemento muito característico da vida franciscana: “Onde há pobreza com alegria, aí não há cobiça nem avareza". ${ }^{64}$ A alegria a que se refere Francisco estabelece uma ponte com a misericórdia e a tomada de consciência sobre a miséria, ${ }^{65}$ que é expressa de modo muito claro na narrativa da Perfeita Alegria. ${ }^{66}$ A pobreza é ponto central dentro da espiritualidade franciscana, pois ela é o modo de manifestação do próprio Deus. Foi Ele que em primeiro lugar esvaziou-se (kenosis) para aproximar-se do ser humano e salválo. ${ }^{67}$ No reconhecimento do valor teológico da pobreza, os termos convergem para uma tomada de consciência de que Deus é nosso único bem e de que muitas coisas do mundo são passageiras.

-O único Rei verdadeiro é Deus.

- O Reino dos Céus, não é conquistado pela sabedoria humana.

- A sabedoria de Deus apresentou-se de forma humilde.

\footnotetext{
${ }^{58}$ Adm 22, 2; Adm 22,3; Adm 23; Adm 23,1;RnB 5,5; RnB 11,3; RnB 17,15; RnB 20,2; RnB 20,5; RnB 23,6; $R n B$ 23,7; RnB 23,11;RB 3,11; RB 5,3;RB 6,2; RB 10,1; 2 Fi 30; 2 Fi 44; 2 Fi 87; 1 Ct 2; Ord 2; Cnt 7; Cnt 14.

${ }^{59} \mathrm{RnB}$ 9,1; RB 12,4; 1 Fi 13; 2 Fi 56; Ord 27; Ord 28.

${ }^{60} \mathrm{Adm} 13,1 ; \operatorname{Adm} 13,2 ;$ Adm 17; Adm 19; RB 10,9.

${ }^{61}$ Adm 27,2; Test 7; 2 Fi 45.

${ }^{62}$ Adm 1,16; Adm 1,17.

${ }^{63}$ Dicionário Franciscano. Petrópolis, RJ: CEFEPAL/Vozes, 1993, p. 355.

${ }^{64}$ Adm 27,3.

$65 \mathrm{Sl} 50$.

${ }^{66}$ Narrativa da Perfeita Alegria. https://www.capuchinhosrs.org.br/procepi/franciscanismo/escritos-de-saofrancisco/fragmentos/ditado-da-perfeita-alegria/ditado-sobre-a-verdadeira-e-perfeita-alegria. Acesso em: 06/12/2021.

${ }^{67}$ ZUNDEL, Maurice. A l'écoute du silence. Paris: Téqui, 1995, p. 101.
} 
- A grandeza e onipotência de Deus se manifestam em forma de misericórdia e salvação.

Portanto, Francisco utiliza constantemente uma teologia do abaixamento dentro de sua espiritualidade, onde os fatos centrais são a encarnação, o processo de crucificação/morte e a Eucaristia. Todos esses momentos da vida de Jesus, Francisco os interpreta à luz da pobreza como autodoação de Deus por amor.

\section{Vós sois beleza - considerações sobre a terceira parte da oração}

Na terceira parte da oração, Francisco invoca Deus como protetor, guarda e defensor. Apenas Ele é a segurança e pode oferecer refrigério. Podemos entender essa proteção de Deus como fonte da segurança sentida por Frei Leão ao receber o manuscrito das mãos de Francisco, ${ }^{68}$ que também apresenta Deus como esperança, unindo a ela as outras duas virtudes teologais, a fé e a caridade. A forma crescente como vão sendo apresentadas as características de Deus faz com que, aos poucos, até os termos aparentemente mais abstratos usados se encarnem de modo bem concreto; Deus é apresentado como amor/caridade, logo em seguida, ele aponta que Deus é toda doçura e nossa e vida eterna.

O emprego do pronome possessivo "nossa", é uma demonstração de como a fraternidade universal é amada por Deus. Marcado pela experiência profunda do amor de Deus no Alverne, Francisco compreende que o existir de cada ser é obra do Criador e necessita constantemente do amor cuja fonte é Deus. O próprio existir de cada criatura é já um ato de louvor, e esse louvor é essencialmente uma oração, portanto, Francisco empresta sua voz às criaturas, para falar com Deus e não sobre Deus. ${ }^{69}$ Ele confraterniza com toda a criação, unida em Louvor, para manifestar que Deus permanece sendo indizível, e que, todos os atributos empregados a Deus ainda permanecem insuficientes. Dentro dessa oração não existe um convite para alguma ação, pois, o ser já é uma forma de manifestar a grandeza do Criador. ${ }^{70}$ A tomada de consciência e o reconhecimento humilde dessa relação de dependência já é o grande Louvor oferecido a Deus.

Dentro dessa oração aparecem claramente elementos da proximidade da Criação com Deus, mas também a consciência da grande superioridade de Deus com relação a toda criação. Deus sempre é visto como uma presença viva, e por isso, tão próximo que suas

\footnotetext{
682 Cel 49.

${ }^{69}$ Aproccio Storico-Critico - Alle Fonti Francescane. Frascati: Giammarioli, 1979, p. 70-71.

${ }^{70}$ Escritos de São Francisco de Assis. 2. ed. Santo André: Mensageiro de Santo Antônio, 1999, p. 239-240.
} 
atitudes são personificadas como: Pai, Rei, Senhor, doce, segurança, quietude, protetor, amor e refrigério. As últimas expressões relembram a grandeza de Deus, "grande e admirável Senhor, Deus Onipotente"; mas, todavia, invocam a misericórdia daquele que é o Go'el intensamente esperado.

Amemos todos com todo coração, com toda alma, com toda mente, com toda força (cfr. Mc 12,30) e fortaleza (cfr. Mc 12, 33), com todo entendimento, com todas as forças (cfr. Lc 10,27), todo esforço, todo afeto, todas as entranhas, todos os desejos e vontades o Senhor Deus (Mc 12,30 par.), que nos deu e nos dá a nós todos todo o corpo, toda a alma e toda a vida, que nos criou, remiu e só por sua misericórdia vai salvar (cfr. Tb 13,5), que a nós miseráveis e míseros, pútridos e fétidos, ingratos e maus, fez e faz todo bem. ${ }^{71}$

A determinação que Francisco tinha em encarnar o seguimento de Cristo faz com que suas orações e escritos estejam bem longe de serem apenas poesias desligadas da realidade. Dentro dos seus escritos existe uma sensibilidade antropológica e inclusive diversas críticas sociais, principalmente àqueles que se afastaram de Deus e vivem conforme o espírito do mundo. Em nenhum momento aparece qualquer expressão negativa dentro dos Louvores. Deus é o perfeito ser, a perfeita existência, Nele não existe falha, ou ausências. Sua potência e grandeza são experimentadas como amor e providência. Por isso, apesar da convicção de sua miséria, Francisco ainda tem confiança na misericórdia de Deus.

\section{Conclusão}

Francisco transforma sua vida em lugar teológico do qual emerge uma compreensão cristológica muito profunda. A manifestação da experiência de Francisco acontece por seus escritos, mas especialmente por meio da sua vida; o agir do Poverello testemunha a autenticidade da sua experiência e fundamenta os seus escritos.

A escola teológica de Francisco foi a Sagrada Escritura filtrada pela Liturgia, contudo, existe uma complementariedade entre a Sagrada Escritura e a Revelação de Deus no mundo. Todo agir de Deus é um desdobramento do seu amor, diante da revelação Francisco louva reproduzindo em si, parte do amor recebido de Deus e oferecendo-o a todas as criaturas em forma de oração. Ainda que as palavras sejam inadequadas e

\footnotetext{
${ }^{71} \mathrm{RnB} 23,8$.
} 
insuficientes para falar sobre Deus, Francisco, ao contemplar a criação e a encarnação, entende que a existência é uma forma de manifestar a gratidão e retribuir a Deus o dom recebido.

Os paradoxos fazem parte da experiência de encontro entre Francisco e o Altíssimo, e também da sua representação de Deus. Coexistem em Deus atributos como Altíssimo e Pai, Rei e mansidão; Onipotente e protetor.... Esses paradoxos geram uma antropologia muito de acordo com a pessoa de Jesus Cristo. Cristo é o ápice da Revelação, mas também é o sentido e fundamento da vida humana.

A compreensão cristológica de Francisco nos Louvores a Deus Altíssimo permite identificar um itinerário de seguimento muito concreto. Cristo é o modelo perfeito de ser humano, tendo isso em vista que a finalidade da vida humana é a identificação e encontro com Deus. A experiência no Alverne é a manifestação sensível da união entre configuração com Cristo e antropologia.

\section{Lista de Abreviaturas}

$1 \mathrm{Ct}$ - Carta aos Custódios ( $1^{\mathrm{a}}$ recensão)

Jo - Evangelho de João

$1 \mathrm{Fi}$ - Primeira carta aos fieis

LH - Louvores de Deus nas horas

1 Ts - Primeira Tessalonicenses canônicas

2 Cel - Segunda vida, de Tomás de Mn - Carta a um ministro

Celano Mt - Evangelho de Mateus

$2 \mathrm{Ct}$ - Carta aos Custódios ( $2^{\mathrm{a}}$ recensão)

Oc - Oração diante do Crucifixo

$2 \mathrm{Fi}$ - Segunda carta aos fieis PN - Paráfrase do Pai-nosso

Adm - Admoestações

RB - Regra Bulada

Ant - Carta a Santo Antônio RnB - Regra não Bulada

Cnt - Cântico do Irmão Sol Sl - Salmos

ExL - Exortação ao Louvor de Deus SV - Saudação às virtudes FV - Forma de vida para Santa Clara Test - Testamento de São Francisco Gv - Carta aos Governantes 


\section{Referências}

Aproccio Storico-Critico - Alle Fonti Francescane. Frascati: Giammarioli, 1979.

BARSOTTI, Divo. Una teologia dell'esperienza di Dio: Le laudes Dei di S. Francesco d'Assisi. In: Contratto, 4 (1995).

BERNARD, Charles Andrè. L'esperienza spirituale della Trinità. In: La mistica. Fenomenologia e riflessione teologica. [II]. Roma: Città Nuova, 1984.

CONCÍLIO ECUMÊNICO VATICANO II. Constituição dogmática “Dei Verbum”. São Paulo: Paulinas, 1966.

Dicionário Franciscano. Petrópolis, RJ: CEFEPAL/Vozes, 1993.

Escritos de São Francisco de Assis. 2. ed. Santo André: Mensageiro de Santo Antônio, 1999.

Fontes Franciscanas e Clarianas. Petrópolis: Vozes, 2004.

FRANCESCO D’ASSISI. Scritti. Grottaferrata: Ad Claras Aquas, 2009.

LANGELI, Attilio Bartoli. Gli autofrafi di frate Francesco e di frate Leone. Turnhout: Brepols, 2000.

LEHMANN, Leonard. Francisco Mestre de Oração. Piracicaba: CEFEPAL, 1997.

MACHADO, Sidney Damasio. L' "Altissimo" e il "Santissimo". Studio semantico e simbolico di due termini chiave degli "Scritti" di san Francesco d'Assisi. Roma: Istituto Storico de Cappuccini, 2019.

MACHADO, Sidney Damasio. Ver para crer: um percurso espiritual artístico e simbólico. São Paulo: Angelus, 2021.

MOLINA PARRA, Néstor Bernardo. El Reino de Dios en el pensamiento eclesiológico y escatológico de san Francisco de Asís, según sus escritos y las fuentes hagiográficas del siglo XIII-XIV. Murcia: Espigas, 2015.

Narrativa da Perfeita Alegria. Disponível em: https://www.capuchinhosrs.org.br/procepi/franciscanismo/escritos-de-saofrancisco/fragmentos/ditado-da-perfeita-alegria/ditado-sobre-a-verdadeira-e-perfeitaalegria. Acesso em: 06/12/2021.

NGUYÊN-VAN-KHANH, Norbert. Gesù Cristo nel pensiero di San Francesco. Milano: Francescana, 1984.

PAOLAZZI, Carlo. Lettura degli Scritti di Francesco d'Assisi. Milano: Francescana, 2015. 
PESSI, Donizeti; MORESCO, Kleber. A estrutura lógica e os limites da descrição do mundo. In: Controvérsia, 15, (2019).

Regra de São Bento. 3. ed. Juiz de Fora: Edições Subiaco, 2016.

ZUNDEL, Maurice. A l'écoute du silence. Paris: Téqui, 1995. 